\title{
Cerebral Hemangioblastoma
}

National Cancer Institute

\section{Source}

National Cancer Institute. Cerebral Hemangioblastoma. NCI Thesaurus. Code C155947.

A hemang ioblastoma that arises from the cerebrum. It may be associated with von

Hippel-Lindau disease. 